\title{
Problem-Solving Skills as Correlates of Attention Span and Working Memory of Low Ability Level Students in Senior Secondary Schools
}

\author{
Barnabas O. Ellah ${ }^{1}$ \\ Emmanuel E. Achor ${ }^{2}$ \\ Veronica Enemarie ${ }^{3}$
}

'Universal Basic Education, Junior Secondary School, Demekpe, Makurdi, Benue State, Nigeria. Email:ellizee_2010@yahoo.com

${ }^{\circ}$ Curriculum and Teaching Department, Faculty of Education, Benue State University Makurdi, Benue State, Nigeria.

${ }^{3}$ Staff School, Benue State University, Makurdi, Benue State, Nigeria, Nigeria.

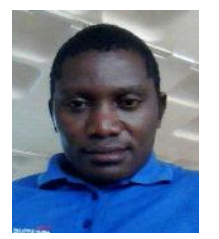

( Corresponding Author)

\section{Abstract}

The study sought to determine the relationship between problem-solving skills and measure of working memory and attention span of science students of low ability level. The study adopted correlational survey research design. The population for the study comprised all Secondary School I (SSI) that offered physics, chemistry and biology as school subjects in all the public senior secondary schools in the study area for 2017/2018 academic session while the sample was 450 science students from 24 Senior Secondary Schools in the study area. Wechsler Adult Intelligence Scale (WAIS) backward digit span task and Attention Lapses Clicker (ALC) were used for data collection. Multiple regression analysis was used to analyse data used to answer the research questions and test null hypotheses at 0.05 level of significance. Findings revealed that low percentage variation in students' problem-solving skills in science can be attributed to measure of working memory and attention span. There exist no significant relationship between measure of working memory, attention span and the combination of working memory and attention span of students. It was recommended among others that science teachers should vary concentration spans of science students by inherently mimicking the same kind of cognitive gear shift in the activities that require creative problem-solving skills and thinking, Also interventions and accommodation need be designed by school administrators to help science teachers differentiate instruction with explanations on how techniques or strategies can address students with working memory difficulty and attention deficits in the classroom.

Keywords: Working memory, Attention span, Problem-solving skills, Ability level, Science.

Citation | Barnabas O. Ellah; Emmanuel E. Achor; Veronica Enemarie (2019). Problem-Solving Skills as Correlates of Attention Span and Working Memory of Low Ability Level Students in Senior Secondary Schools. Journal of Education and e-Learning Research, 6(3): 135-141.

History:

Received: 25 March 2019

Revised: 1 May 2019

Accepted: 4 June 2019

Published: 28 August 2019

Licensed: This work is licensed under a Creative Commons Attribution 3.0 License (cc) E E

Publisher: Asian Online Journal Publishing Group
Acknowledgement: All authors contributed to the conception and design of the study.

Funding: This study received no specific financial support.

Competing Interests: The authors declare that they have no conflict of interests.

Transparency: The authors confirm that the manuscript is an honest, accurate, and transparent account of the study was reported; that no vital features of the study have been omitted; and that any discrepancies from the study as planned have been explained.

Ethical: This study follows all ethical practices during writing.

\section{Contents}

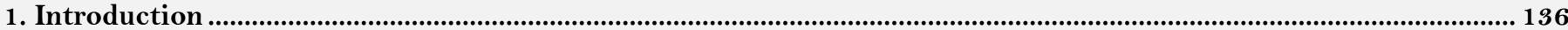

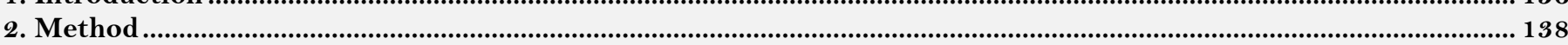

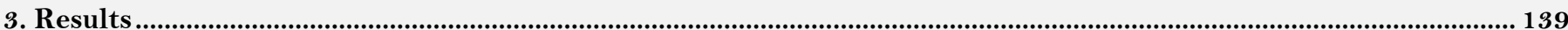

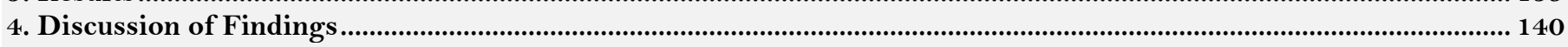

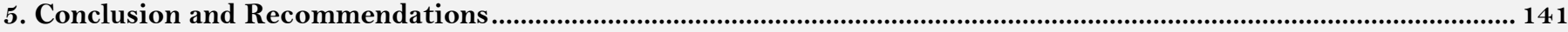

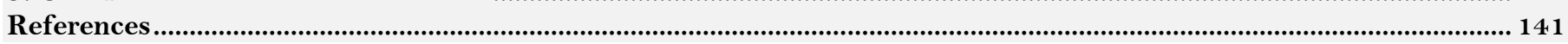




\section{Contribution of this paper to the literature}

The study provided practical information and framework to future researchers particularly as it concerns the relationship between problem-solving skills and measure of working memory and attention span of science students of low ability level as it was found that low percentage variation in students' problemsolving skills in science can be attributed to measure of working memory and attention span. The study has shown that no significant relationship exist between problem-solving skills and combination of working memory and attention span of science students of low cognitive ability level. The study has contributed to knowledge in form of provision of empirical data that adds to the existing body of knowledge on relationship between problem-solving skills and measure of working memory and attention span in promoting students' achievement in science in Benue State. Such data had not existed before to the best of the researcher knowledge.

\section{Introduction}

The economic development and social welfare of any nation has a strong connection with the level of her scientific and technological advancements. Science subjects are important in helping students to possess the depth of knowledge and skills to assure these scientific and technological advancements. The application of these science subjects in industry and many other fields makes it crucial for a conducive living in the modern age of science and technology (Pember, 2014). Furthermore, the knowledge and application of these science subjects is required in computer and system designs, robotics, metallurgy, radio and television transmission, electronics, medicine, satellites, engineering, energy generation, fibers, optics, environmental protection, and mining and prospecting. It is in this realization that Keith (2011) stresses that careers such as defense, health service, aerospace, agriculture, metallurgy, alternative energy (Geothermal, solar, wave and wind), food preservation/processing, education, instrumentation, weather forecast and so on are embedded in the applications of several science related fields. Pember (2014) further stressed that for students wishing to study courses like engineering, medicine, pharmacy, agricultural science, geology, pharmaceutical science and science allied courses at the tertiary level at least a credit pass in these science subjects in Secondary School Certificate Examination (SSCE) is one of the requirements. Inspite of the crucial role science subjects plays in the technological advancement of a nation; the teaching and learning of these subjects (biology, chemistry and physics) in Nigeria schools is facing a lot of challenges.

Science has much to do with abstractions, conceptual thinking and generalization of facts, which has much to do with cognition also. Achievement of effective cognitive processing of scientific concepts and the attainment of formal operational stage are therefore imperative. The reason for this is that at formal operational stage the students are expected to operate logically via serration, classification, casualty, time as well as speed. Thus students are also able to combine ideals, attempt to solve verbal and hypothetical problems which also implicate proportions and kinetic conservation. As a follow up, transfer of understanding from one situation to the other is enhanced. Science contents often require logical thinking (Adeyemo, 2010).

Also related to the attainment of formal operational stage that supports the transfer of understanding from one situation to the other is the attention span of students during science lessons. Karen and Korn cited in Briggs (2014) states that science students' attention lapses during the initial minutes of settling-in, again at 10-18 minutes into lesson, and then as frequently as every 3-4 minutes toward the end of the lesson. Researchers then have the liberty to report lapses in attention and became more or less frequent or stayed the same as the teacher switches from one method to another. Further Briggs states that the length of science students' concentrate during lessons depend on their attention span which ranges from 10 to 15 minutes, even at this most science classes last more than 40 minutes and sometimes double periods (that is, 80 minutes).Students' attention spans vary from individual to individual and are widely influenced by factors like motivation, emotion, anxiety, fatigue, enjoyment, time of day among others. Solving complex, multi-component problems requires skills that depend on the students' level of concentration and the mental effort to carry it out. This is because, students who evidence problem such as inattention and distractibility may have problem with encoding of information. Again, students who have difficulty paying attention to specific information struggle with the encoding of such information. This is because attention as a cognitive process enables working memory to hold information when students perform cognitive tasks and that serves as behaviour modifier on a task. The inability to regulate attention is directly related to students' performance which is their ability level (Silvana and Robert, 2010). Attention span is very important for the students to make effective and efficient use of skills in the process of solving problems. Attention span is highly related to the achievement of complex cognitive tasks by the student which is working memory.

Working memory is the term used to refer to a brain system responsible for temporarily storing and manipulating information. It functions as a mental workspace which can be flexibly used to support everyday cognitive activities. Those activities require both the simultaneous processing and storage of information (Meltzer, 2010). Besides, according to Silvana and Robert (2010) performance on higher level cognitive tasks such as reasoning, reading among others are more accurately predicted by performance on working memory tasks compared to short-term memory tasks. Working memory is considered to have limited capacity. According to Naveh-Benjamin et al. (2007) the memory span of young adults was around seven elements plus or minus. A minor distraction such as an unrelated thought springing to mind or an interruption by someone else is likely to result to incomplete loss of the stored information. Weak verbal working memory skills are also characteristic of poor performance on arithmetic (Alloway, 2006).

Working memory plays an important role in science lessons. How much information working memory can process is time bound. Therefore, science teachers must make their lesson interesting and appealing to their students, the students must use this information which is temporarily stored in working memory to contribute in the class. Since the higher the students' working memory, the better and faster s/he makes contributions and the greater the proportion of correct answers. Conversely, the working memory size determines the time it takes individual to process a given information. Makovski et al. (2008) found that working memory span and processing time were negatively correlated with each other. The understanding of the nature of the relationship between working memory and academic achievement or cognitive ability has widespread implications for both practice and theory of education (Rohde and Thompson, 2007). This necessitates the current investigation. 
The academic potentiality is a factor that determines the capacity of students to engage in meaningful educational task that requires higher cognitive functioning. This could be tagged ability or level of academic attainment and it means the functioning mode characteristic of an individual on display in an intellectual activity in a very consistent and persuasive manner (Ellah, 2014). Three ability levels exist in relation to teaching and learning situation and they high, medium and low levels. High ability learners prefer isolation and social distance as well as theoretical and abstract task. The high ability individuals have greater ability to structure information and solve problems. Medium ability level learners excel better on learning activities involving social materials, and tended to require externally defined goals and reinforcements.

The high ability learners perform better in science courses when compared with low and medium ability a learner which is a mark of high level of intelligence. Cognitive functioning as a measure of intelligence is reflected in the ability to understand ideas and to utilize abstract symbols to solve mental problems. Low ability level learners perform below average and this is attributed to social disadvantages leading to under-achievement (low income, poor health, etc.).

Essential science skills are required for better performance in science. These skills are necessary for use in both the classroom and out of the classroom interactions. According to Martinez (2010) students require capacity to solve complex problem in the technology driven society. This informs why some institutions regard skills in problem-solving as a necessary outcome expected of all students. Consequently science students in the science learning process are expected to acquire skill of identification, definition and problem solving. The concepts in subjects like biology, chemistry and physics present students the opportunity to engage problem-solving skills frequently. The primary goal of learning major concepts and principles of physics is to develop in them problemsolving skills. Thus problem-solving skill cannot be over emphasized quantitatively and qualitatively in teaching and learning of science.

Definition of what is meant by the problem-solving among different authors surprisingly consistent. For example, Ornek (2009) states that, problem-solving is the process of moving towards a goal when the path to the goal is uncertain. Similarly, when a student is confronted with a problem and the solution is not immediately in sight, a problem therefore exists. One harmony within these definitions is the perceived difficulty of the task. Perception of different tasks as problems or difficulties varies among learners. Demands from tasks on students therefore differ and also depend on students' prior understanding (Ormond, 2006). Difficulty therefore announces the presence of problem.

Problems differ infinitely in their structure and demand. There are problems that are straightforward and in which case desired goal/s are clearly stated, and for which all information needed to solve the problem are correctly presented and such problems are said to be well defined. On the other extreme are problems that the desired goal appears uncertain indicating absence of clear information and for which there might be general possible solutions, and they are regarded as unclear problems. A problem being perceived as well thought-out, well-defined or unclear is tied to individual's expertise. Thus individuals may differ in their strategies of solving problem. For expert problem-solvers, it is likely they may be represented with a problem and they know instantaneously the ladder to use in solving it and to such it can be regarded as an exercise rather a problem.

There are seven steps that describe a problem solving cycle. Adeyemo (2010) lists them as recognizing the existence of a problem, and then identify it before defining and representing the problem. Further, there is the need to develop a strategy or plan to help arrive at a solution, recognition of applicable knowledge and then allocate mental and physical resources. The monitoring of the progress towards the goal and evaluating the solution are the last two steps. How you identify, define and represent a problem is mediated by a variety of internal and external factors. Within individuals, existing knowledge and expectations determine how they interpret a problem and their capacity to represent the problem skillfully. Individual differences in abilities and dispositions are other factors that can also affect the problem-solving process. Take for instance, persons with high spatial abilities are more likely to represent problems with the use of images rather than linguistically. There is external factor of social context (that is, peers, one's culture and Language spoken) do affect the type of problem that can be recognized by a group or individual and even the terms can be used to describe it.

The ideas of trial and error and stimulus response as advanced by Edward Thondike were the early supporting theories put forward by psychologists. Subsequent development provided evidence that the trial and error approach to problem solving was not effective and that it works if the possibilities to be tried out are few. This turned the attention of psychologists completely to stimulus response as a way forward in problem solving. Further, and as expressed by Ormrod (2004) research focus by early psychologists shifted to research processes that can be practically observed and measured leading to neglect of internal process that is equally important. Cognitive perspective appears to have swallowed the behaviourists approaches that are still relevant.

The shift in the field eventually developed into information processing theory, which remains a prevalent theory today. Information processing theory of memory therefore is the basis for contemporary theories of learning and problem-solving today. This theory asserts that information in the brain is stored as short term or working memory and long term memory. Working memory is utilized to process information about the problem and maintains its accessibility during the problem-solving process. And because working memory had limited storage capacity, it is often a challenge to use it to solve complex problem. This explains why external storage facilities with larger capacity such as calculator, notebook and computer are used for storage which could be recalled when needed. This also frees available storage space for subsequent use. Also, some skills in problem-solving can be traced until they become automatic, which could minimize the use of working memory capacity. In addition to utilizing short-term memory, problem-solving require accessing relevant information, which is the solvers knowledge base about the problem stored in long-term memory. Critical factors in this retrieval of information include what has been stored, how it is has been stored, and the patterns present in the problem that help the individual perceive what information to access from memory. In order to retrieve information, knowledge from a content domain must be present in memory to begin with; it should also be organize in a way that facilitates its retrieval in an appropriate context. 
With experience in a context domain, it is believed that problem-solvers develop cognitive called problem schemata that allow them to recognize a problem as belonging to a particular category (Sweller, 2010). This mental classification of problem types can trigger particular actions for solving the problem, based on the perceived similarity of the presented problem to the same category of others stored in memory. The cognitive approach to problem-solving involves also the concept of meta-cognition, which refers to an individual's awareness of his or her own thinking process (Martinez, 2010). In the opinion of Mohammed (2015) meta-cognitively engaged problemsolvers have skills for planning their approach in solving the problem, monitor their progress toward the goal as they execute their plan, and also evaluate how effective the chosen strategies could be. Thus meta-cognitive problem-solvers are careful in evaluating their assumptions and hardly indulge in unproductive strategies. This enables them become successful complex problem solvers.

In explaining problem-solving skills distinction must be drawn between algorithm and heuristics (Ormrod in Adeyemo (2010)). While algorithm applies to step-by-step procedures that could guarantee a correct solution at all times, if and only if applied correctly, heuristic is a general strategy or guide for solving problems. The four step problem solving skills as given by Polya in Adeyemo (2010) includes understands the Problem, identifying the unknown, the data ends the condition, and then drawing a figure and introducing a suitable notation. The second step brings out the plan through which the solver seeks a connection between data and unknown. Where an immediate connection does not exist, a related problem or problems that have already been solved becomes a reference point. A third step involves executing the plan made in step two and each step is checked for corrections. Finally is a step to look back to examine the problem solution and arguments are cross examined.

Research literatures on problem-solving skills have shown that experienced or expert problem-solvers solve problems by interjecting an additional step of a quantitative analysis or a low-detail overview of the problem before writing down equations, store principles in memory as chunks of information that are connected and can be usefully applied together while the inexperienced or novices' end to spend little time representing the problem and quickly jump into quantitative expressions, include haphazard formula-seeking and solution pattern matching, inefficiently access each principle or equation individually from memory. Certainly the nation gets nowhere as long as there exists poor problem-solving skills amongst students especially in science.

The revised National Policy on Education (Federal Republic of Nigeria, 2014) as well as the national curriculum for Physics, Chemistry and Biology were prepared with emphasis on use of innovative teaching strategies that address both principles and practices. Poor acquisition in problems-solving skills in science related courses and lag of students in entering formal operational stage (that is, the age at which students can think in abstraction and logically) have been linked to poor performance among secondary school students. Not with standing, no systematic efforts have been made to teach problems-solving skills and the combination of working memory and attention span that involve both general and specific underlying abilities. This study therefore focuses on low ability level students, their working memory and attention span in relation to problem-solving skills in science subjects. As this may be the potent factors responsible for the persistent poor learning outcomes of students.

\subsection{Research Questions}

The following research questions guided the study:

1. What is the relationship between measure of working memory and problem-solving skills of science students of low cognitive ability level?

2. What is the relationship between measure of attention span and problem-solving skills of science students of low cognitive ability level?

3. What is the relationship between problem-solving skills and the combination of working memory and attention span of science students of low cognitive ability level?

\subsection{Hypotheses}

The following null hypotheses were formulated and tested at 0.05 level of significance:

1. There is no significant relationship between measure of working memory and problem- solving skills of science students of low cognitive ability level.

2. There is no significant relationship between measure of attention span and problem-solving skills of science students of low cognitive ability level.

3. There is no significant relationship between problem-solving skills and the combination of working memory and attention span of science students of low cognitive ability level.

\section{Method}

A correlational survey research design was adopted for the study. The study was conducted in Otukpo, Ogbadibo and Okpokwu Local Government Areas of Benue State. The population for the study comprises 2138 science students in the public senior secondary schools in the study area. The sample of the study was 450 SSI students from 24 public senior secondary schools in the study area. The sampled schools were drawn using simple random sampling technique through the use of lucky dip with replacement and the researcher purposively selected 24 intact classes of the secondary schools in the Local Government Areas used for the study. This is because purposive sampling enables the researcher to select those schools that satisfy certain requirements and criteria critical to the research objectives. The instrument for data collection was Wechsler Adult Intelligence Scale (WAIS) backward digit span task and Attention Lapses Clicker (ALC). The WAIS backward digit span task was used to measure working memory. This is part of the Wechsler Adult Intelligence Scale-Third Edition (Wechsler, 1997). Respondents were shown a series of numbers and letters, on a computer screen, and asked to orally recall the numbers first, from lowest to highest, and then letters in alphabetical order. They were given six short practice trials before beginning. The set sizes started at two items, one number and one letter. The series of numbers and letters increased by either one number or one letter as long as they correctly answered one in a set of three. They were also given three trials at each set size. If they did not get any correct in a set then the task was ended. 
Using the Attention Lapses Clicker (ALC), the students were asked to report attention lapses by pressing a button on their clickers after they became aware that they had experienced a period of inattention. The students clicked one button to indicate an attention lapse lasting 1 minute or less, another button to indicate a lapse of 2 to 3 minutes, and a third button to indicate a lapse of 5 minutes or more. The clicker-responses were sent to a computer, and this information was mapped onto a timeline and used to measure the average length of the students' reported attention lapses. However, Students' Cognitive Ability Levels (SCAL) was obtained from the students SSI biology, chemistry and physics promotion examination results. Therefore, baseline data were collected for all the respondents to help determine their cognitive ability levels. The raw scores obtained in each subject was first converted to $\mathrm{Z}$-score then added to obtain the $\mathrm{Z}_{\mathrm{T}}$-score for each student. The $\mathrm{Z}_{\mathrm{T}}$-score was then converted to $\mathrm{T}$ score; a T-score of 45 and below was considered low ability level while the T-score of 46 to 70 was considered as average but 71 and above are considered high ability level students. The instruments were face validated by three experts in Measurement and Evaluation from Science Education Department, University of Nigeria, Nsukka. Data collected were analyzed using multiple regression analysis to answer the research questions and test the null hypotheses.

\section{Results}

Table-1. Regression analysis of measure of working memory and problem-solving skills of science students.

\begin{tabular}{c|c|c|c|c}
\hline Model & R & R Square & Adjusted R Square & Std. Error of the Estimate \\
\hline 1 & $.049^{\mathrm{a}}$ & .002 & .000 & 3.85 \\
\hline
\end{tabular}

Table 1 shows the regression analysis of working memory and problem-solving skills of science students of low cognitive ability level. The analysis implies that the correlation between student working memory and problem-solving skills of science students is 0.049 with a coefficient of determination of 0.002 . This revealed that $0.2 \%$ variation in problem-solving skills can be accounted for by their working memory.

\begin{tabular}{|c|c|c|c|c|c|c|}
\hline \multicolumn{2}{|c|}{ Model } & Sum of Squares & Df & Mean Square & $\mathbf{F}$ & Sig. \\
\hline \multirow[t]{3}{*}{1} & Regression & 15.942 & 1 & 15.942 & 1.071 & .301 \\
\hline & Residual & 6670.789 & 448 & 14.890 & & \\
\hline & Total & 6686.731 & 449 & & & \\
\hline
\end{tabular}

Table 2 shows that the probability associated with the calculated value of $\mathrm{F}(=1.071)$ is 0.05 . Since the probability value of 0.301 is greater than 0.05 level of significance, the null hypothesis was not rejected. Thus, there is no significant relationship between measure of working memory and problem-solving skills of science students of low cognitive ability level.

Table-3. Regression analysis of measure of attention span and problem-solving skills of science students.

\begin{tabular}{c|c|c|c|c}
\hline Model & $\mathbf{R}$ & R Square & Adjusted R Square & Std. Error of the Estimate \\
\hline 1 & .052 & .003 & .000 & 7.65 \\
\hline
\end{tabular}

Table 3 indicates the regression analysis of attention span and problem-solving skills of science students of low cognitive ability level. The analysis implies that the correlation between student attention span and their problemsolving skills is 0.052 with a coefficient of determination of 0.003 . This revealed that $0.3 \%$ variation in problemsolving skills can be attributed to their attention span.

Table-4. Analysis of variance of measure of attention span and problem-solving skills of science students.

\begin{tabular}{|c|c|c|c|c|c|c|}
\hline & Model & Sum of Squares & df & Mean Square & $\bar{F}$ & Sig \\
\hline \multirow[t]{3}{*}{1} & Regression & 71.386 & 1 & 71.386 & 1.218 & .270 \\
\hline & Residual & 26250.694 & 448 & 58.595 & & \\
\hline & Total & 26322.080 & 449 & & & \\
\hline
\end{tabular}

Source: SPSS output of field work (2019).

Table 4 shows that the probability associated with the calculated value of $\mathrm{F}(=1.218)$ is 0.05 . Since the probability value of 0.270 is greater than 0.05 level of significance, the null hypothesis was not rejected. Thus, there is no significant relationship between measure of attention span and problem-solving skills of science students of low cognitive ability level.

Table-5. Regression analysis of problem-solving skills and the combination of working memory and attention span of science students.

\begin{tabular}{c|c|c|c|c}
\hline Model & R & R Square & Adjusted R Square & Std. Error of the Estimate \\
\hline 1 & .076 & .006 & .001 & 1.15 \\
\hline \multicolumn{5}{l}{ Source: SPSS output of field work (2019). }
\end{tabular}

Table 5 shows the regression analysis of problem-solving skills and the combination of working memory and attention span of science students of low cognitive ability level. The analysis implies that the correlation between student problem-solving skills and the combination of working memory and attention span is 0.76 with a coefficient of determination of 0.006 . This revealed that $0.6 \%$ variation in problem-solving skills can be explained by the combination of working memory and attention span. 
Table-6. Analysis of variance of problem-solving skills and the combination of working memory and attention span of science students

\begin{tabular}{c|c|c|c|c|c|c}
\hline \multicolumn{2}{c|}{ Model } & Sum of Squares & df & Mean Square & F & Sig \\
\hline \multirow{3}{*}{1} & Regression & 1.427 & 1 & 1.427 & 1.071 & .301 \\
\cline { 2 - 7 } & Residual & 596.964 & 448 & 1.333 & & \\
\cline { 2 - 7 } & Total & 598.391 & 449 & & & \\
\hline
\end{tabular}

Source: SPSS output of field work (2019).

Table 6 shows that the probability associated with the calculated value of $\mathrm{F}(=1.071)$ is 0.05 . Since the probability value of 0.301 is greater than 0.05 level of significance, the null hypothesis was not rejected. Thus it can be concluded that there is no significant relationship between problem-solving skills and the combination of working memory and attention span of science students of low cognitive ability level.

\section{Discussion of Findings}

A strength of the current study lies with the inclusion of the measure of attention span and working memory alongside problem-solving skills of low cognitive ability level students. This allows for a more in-depth investigation of the contribution of different aspects of problem-solving skills to the assessment of scientific skills of low ability science students.

The findings of the study show that low percentage of variation in low ability students' problem-solving skills in science can be attributed to their measure of working memory. However, the low positive correlation between students' measure of working memory and problem-solving skills shows a no statistically significant relationship. This might be due distractions during the memory test. The finding is in agreement with earlier findings of Yuan et al. (2006) that positive relationships exist between working memory and science learning. Wiley (2015) that training programme led to improvements in both meta-cognitive and working memory tasks, with positive-related effects on the ability to solve problems.

The results support the assumption that problem-solving impairs and reduce working memory capacity as well as hampers cognitive ability level of science students. The greater and more stressful the problem to be solved the smaller the working memory capacity that would be used. However, the greater the working memory capacity a student applied, the better s/he is able to solve problems skillfully. If students can keep track of information then they might not have to keep looking back to refresh their memory or risk losing them but should be able to solve problems better and faster base on available information that can be remembered. However, the mental space that is involved in the controlling, regulating, and maintaining of relevant information needed to solve complex cognitive tasks seems to be important for problem-solving skills. Subsequently, the relationship between problemsolving skills and the combination of working memory is far from being clear.

The research results obtained from the data analysis indicate that there is no significant relationship between students' measure of attention span and problem-solving skills of low cognitive ability level in science. Similarly, no significant relationship was found between problem-solving skills and the combination of working memory and attention span of low ability level students. These findings are in disagreement with the findings of Konig et al. (2005) that through hierarchical multiple regression analyses, working memory was the most important predictor in addition to attention and fluid intelligence.

However, the low positive correlation found might be attributed to inadequate acquisition of problems-solving skills as result of ability level. Besides, most science teachers in most secondary schools used for the study have zero or poor approximate mixture of knowledge, skill and attitude towards teaching. Teachers are paid to help students acquire the necessary knowledge, skills and attitude that are enablers in performance of certain activities to the expected standard when required. Cultivation of the habit of seeking for problems to solve as means of selfcheck on competency and extent to which knowledge is gained in other to improve on their ability level is expected of students.

The science teachers may be challenged by the students' overall attention span or ability to concentrate in the classroom. However, there are many quick and easy activities the teacher can incorporate into the teaching and learning process to build students' capacity for maintaining focus. We live in a time where, as teachers, we often find ourselves competing for the attention of our students. Computers, tablets, and smart phones have granted students virtually unlimited access to information while simultaneously decreasing their natural attention spans. Attention and focus have to be built up over time in students by engaging them in problem-solving activities as a gate way, especially when design activities require students to use their working memory to be successful. Engaging students in activities where they have to concentrate on their physical position also helps build their attention span and focus. One way to build students' ability to concentrate in the classroom is to deliberately give them concentration breaks during instruction during long periods of class work. This helps the brain to reset and rest so that it can come back to the task at hand with renewed focus.

Problem-solving is an integral part of science learning irrespective of the students' ability levels. Problemsolving is one of major aspects in science teaching and learning which requires science students of different ability levels to apply and integrate many scientific concepts and skills in and outside the classroom situation. Students learn and understand science subjects through solving mathematically and scientifically rich problems and problem-solving skills are developed through learning and understanding scientific concepts and procedures. Lack of many mathematical and scientific skills may be responsible for the difficulties in making inference and solving problem encountered by students that reduce their low ability level. Many students who struggled to accomplish in science especially problem-solving are the low cognitive ability levels.

Students must be able to solve problems because problem-solving is important for the improvement of ability levels. In real life, students need to solve problems because that is a basic way to survive in our daily-living. The secondary science curriculum emphasized on arithmetic; problem-solving, communication, mantic-thinking, connection-building and technology application skills. The no significant relationship found in this study could be due to deficiency in cognitive ability level which is largely responsible for the difficulty in differentiating, relating and organizing information meaningfully as well as drawing inferences. 


\section{Conclusion and Recommendations}

Based on the findings of this study, it was concluded that students' measure of working memory and attention span are not influential factor in problem-solving skills of science students of low cognitive ability level at secondary education level. This is due to the low positive correlation found. Correspondingly, no statistically significant relationship was found between students' measure of working memory, attention span or the combination of working memory and attention span and problem-solving skills of low cognitive ability level science students. Therefore, the specific activities focusing on attention span and working memory could not contribute to modifying scientific problem-solving skills of low cognitive ability level. This could be due to some other factors either on the part of the students, parents, teachers or environment of the study among others. Based on the findings of the study, the following recommendations were made:

1. Science teachers should vary concentration spans of science students by inherently mimicking the same kind of cognitive gear shift in the activities and ideas to facilitate hands-on, practical or inquiry-based learning experiences that require creative problem-solving skills and thinking.

2. Science teachers need to undergo further retraining in workshops and seminars to acquire necessary skills on building up of students' problem-solving skill.

3. Science teachers should give concentration breaks during instruction of long periods to enable brain reset to come back to a task at hand with renewed focus.

4. Interventions and accommodation should be designed by school administrators to help science teachers differentiate instruction with explanations on how a strategy can address students' working memory and attention deficit in the classroom.

\section{References}

Adeyemo, S.A., 2010. Students ability level and their competence in problem solving task in physics. International Journal of Educational Research and Technology, 1(2): 35-47.

Alloway, T.P., 2006. How does working memory work in the classroom? Educational Research and Reviews, 1(4): 134-139.

Briggs, S., 2014. The science of attention: How to capture and hold the attention of easily distracted students. Available from http://www.opencolleges.edu.au/informed/features/30-tricks-for-capturing-students-attention/\#ixzz36MZ6pRXx [Accessed August 7, 2018].

Ellah, B.O., 2014. Cognitive style and attitude to science of senior secondary school science students of different ability levels. (Unpublished Dissertation), University of Nigeria Nsukka, Enugu State. Nigeria.

Federal Republic of Nigeria, 2014. National policy on education. Abuja: NERDC Press.

Keith, D., 2011 . Advanced physics. 2nd Edn., India: Repro India, Ltd. NaviMumdai.

Konig, C.J., M. Buhner and G. Murling, 2005. Human Performance, 18(3): 243-226.

Makovski, T., R. Sussman and Y.V. Jiang, 2008. Orienting attention in visual working memory reduces interference from memory probes. Journal of Experimental Psychology: Learning, Memory, and Cognition, 34(2): 369-380.Available at: https://doi.org/10.1037/0278-7393.34.2.369.

Martinez, M.E., 2010. Learning and cognition: The design of the mind. Upper Saddle River: Pearson.

Meltzer, L., 2010. Promoting executive function in the classroom. New York: The Guilford Press.

Mohammed, K.A., 2015. The effect of using meta-cognitive strategies for achievement and the trend towards social studies for intermediate school students in Saudi Arabia. International Journal of Education, Learning and Development, 3(7): 47-54

Naveh-Benjamin, M., J. Guez and S. Sorek, 2007. The effects of divided attention on encoding processes in memory: Mapping the locus of interference. Canadian Journal of Experimental Psychology, 61(1): 1-12.Available at: https://doi.org/10.1037/cjep2007001.

Ormond, J.E., 2006. Educational psychology: Developing learners. 5th Edn., Upper Saddle River, New York: Pearson Education, Inc.

Ormrod, J.E., 2004. Human learning. 4th Edn., Upper River, NJ: Pearson Education, Inc.

Ornek, F., 2009. Problem-solving: Physics modeling-based interactive engagement. Asia-Pacific Forum on Science Learning \& Teaching, $10(1): 1-35$.

Pember, S.T., 2014. Effect of computer simulation experiments on senior secondary students' practical physics achievement and interest in physics in education zone A, Benue State. (Unpunished Thesis) Benue State University, Makurdi, Nigeria.

Rohde, T.E. and L.A. Thompson, 2007. Predicting academic achievement with cognitive ability. Intelligence, 35(1): 83-92.Available at: https://doi.org/10.1016/j.intell.2006.05.004.

Silvana, M.R. and A.G. Robert, 2010. Using knowledge of students' cognition to differentiate instruction. North California: Chapel Hill.

Sweller, J., 2010. Cognitive load theory, educational research, and instructional design: Some food for thought. Instructional Science, 38(2): 105-134.

Wechsler, D., 1997. Wechsler adult intelligence scale. 3rd Edn., San Antonio, TX: Psychological Corporation.

Wiley, J., 2015. Improving problem solving in primary school students: The effect of a training programme focusing on meta-cognition and working memory. British Journal of Educational Psychology, 8(3): 424-439.

Yuan, K., J. Steedle, R. Shavelson, A. Alonzo and M. Oppezzo, 2006. Working memory, fluid intelligence, and science learning. Educational Research Review, 1(2): 83-98. 